UDC: 821.163.41.09-1:398]:821.134.1.09

$821.163 .41^{\prime} 255.4=134.1$

DOI: https:// doi.org/10.18485/beoiber.2021.5.1.6

\author{
Hristina Vasić Tomše ${ }^{1}$ \\ Universitat de Ljubljana \\ Eslovènia
}

\title{
«LA NINA Y EL PEIX». TRADUCCIÓ INDIRECTA D’UNA CANÇÓ POPULAR ESLAVA
}

\begin{abstract}
Resum
El present article és resultat de la recerca sobre la traducció catalana d'una cançó popular eslava que va ser publicada l'any 1896 a la revista L'Aureneta sota un dels pseudònims del poeta Josep Carner.

Partint de la cançó popular «Riba i djevojka», publicada en el Cançoner popular serbi (1815) recopilat per Vuk Stefanović Karadžić, a l'article es reconstrueix i contextualitza el camí que la cançó va recórrer fins arribar a Catalunya. A continuació s'estableix la font que va servir de base per a la traducció catalana. A fi de reconstruir la feina de Carner en traduir i recrear els versos de la cançó popular, s'analitzen els canvis de lèxic, estil i mètrica que apareixen en la versió carneriana respecte a l'original i la traducció intermediària.

La traducció de Carner representa l'única traducció catalana d'aquesta cançó popular coneguda fins ara, i molt probablement és així mateix l'única creació de la poesia popular dels Balcans que s'hagi traduït mai al català.
\end{abstract}

Paraules clau: Josep Carner, poesia popular eslava, traducció, cançó lírica, Vuk Stefanović Karadžić.

\section{"LA NINA Y EL PEIX". INDIRECT TRANSLATION OF A SLAVIC LYRIC FOLK SONG}

\section{Summary}

The present article is a research on the Catalan translation of a Slavic lyric folk song. The translation has been published in the magazine L'Aureneta in 1896, the author of the translation being Josep Carner using one of his pseudonyms.

As a starting point we use the variation of the song "Riba i djevojka" form the Serbian Folk Song Book (1815) compiled by Vuk Stefanović Karadžić. In the article we try to reconstruct and contextualise the path that the song has taken to get to Catalonia. Next, we establish the source that served as the basis for the Catalan translation. In order to reconstruct Carner's work in translating and recreating the verses of the folk

${ }^{1}$ hristina9@gmail.com

BEOIBERÍsTICA Vol. V / Número 1 (2021) | 93-106 
song, we analyse the changes in vocabulary, style, and meter that appear in Carner's version with respect to the original and the intermediate translation.

The translation of the young Carner is the only Catalan translation of this folk song known to date, and is likely the only example of Balkan folk poetry that has ever been translated into Catalan.

Key words: Josep Carner, Balkan folk poetry, translation, lyric song, La nina y el peix.

L'any 1896 va aparèixer a L'Aureneta una cançó lírica d'estil popular amb l'única referència que era una traducció d'una cançó que formava part de la literatura eslava. A sota de la cançó, intitulada «La nina y el peix», s'hi llegia: «Enrich». Amb aquest pseudònim es presentarà a L'Aureneta l'autor vertader de la traducció, que aleshores era un nen de dotze anys. Aquest nen es farà, amb el pas de temps, el príncep dels poetes en llengua catalana. Serà llegit, estudiat, traduït, i un dia també arribarà a una classe del màster d'estudis catalans a la Universitat de Barcelona, on es practicarà l'edició de textos a partir de les variants dels poemes carnerians i d'on partirà la idea de trobar la font de l'esmentada traducció d'un poema eslau. Aquesta recerca em portarà fins a la font que va servir de base a la versió en català, però igualment em proporcionarà informacions per poder reconstruir el camí que va recórrer aquesta cançó popular fins arribar a Catalunya².

\section{La font}

Tot va començar el primer quadrimestre en una classe del professor Jaume Coll. En saber que jo era sèrbia, em va assabentar que la primera traducció publicada per Carner formava part de la cultura eslava, i em va demanar si podria donar un cop d'ull al text per veure si hi reconeixia una cançó tradicional sèrbia. Em va mostrar el poema, publicat a L'Aureneta el 6 de juny de 1896. A la rúbrica hi figurava «Literatura Eslava». El títol era «La nina y el peix», a sota del qual s'hi llegia: «(Traduhit)» i al peu del poema: «Enrich», un dels pseudònims segurs del Carner de L'Aureneta.

\section{LA NINA Y EL PEIX \\ Una bella nina \\ n'estava sentada \\ vora de la mar,}

\footnotetext{
2 Els resultats de la recerca van ser presentats a les Jornades Carner a l'Edifici Carner, celebrades a la Universitat de Barcelona entre el 9 i el 11 de febrer de 2009.
} 
vora la mar blava,

y ab sa dolsa veu

aixís ne parlava:

- ¿Hi ha alguna altre cosa

que la mar, mes vasta?

$¿$ Hi ha alguna cosa

que sia estimada

com un bon germà,

com una germana?

¿O que hi ha mes dols

que la mel? - Del aygua

va sortir un peixet

qu'aixís contestava:

- Lo cel es mes vast

qu'aquesta mar blava

l'aymant mes volgut

qu'un germà o germana

mes dolsa que la mel

n'es una abrassada.

(«La nina y el peix» 1896: 3)

Sí que m’era familiar el poema, però res més. La procedència del poema que ens va donar el seu traductor es referia a una cultura tan àmplia i variada que incloïa gairebé un terç de la creació popular europea. Pensant-hi, creia que la possibilitat que la cançó formés part de la cultura sèrbia era gairebé nul la, però aquest to senzill, molt ben reproduiit, de l'esperit del poble balcànic no em deixava estar-ne segura. Per tant, em vaig dirigir a un company de Sèrbia que es dedica precisament a la traducció de la poesia popular. L'única cosa que tenia era la procedència aproximativa de la cançó. Però havia de creure que provenia exactament dels Balcans i amb aquesta fe continuar la recerca.

Primer vaig trobar una cançó de dos anys enrere que cantava un músic serbi anomenat Van Gogh. La cançó és deia «Ludo luda»³ (Van Gogh 2008) i era la versió

\footnotetext{
${ }^{3}$ Transcric la lletra de la cançó «Ludo luda» («Boja bojeta»), tot seguit traduïda al català: «Devojka sedi kraj mora sama i tiho sebi govori: / "Ah, mili Bože, da li ima, ima'l što šire od mora?" / "Ludo luda, mlada si devojko!", riba iz vode joj govori: / "Ima, luda ludice devojko, šire je nebo od mora mog". / Devojka sedi u polju sama i tužno sebi govori: / "Ah, mili Bože moj, imaš li odgovor / šta je to draže od brata mog?" / "Ludo luda, mlada si, devojko", ptica iz polja joj govori / "Ima, luda ludice devojko, draži je dragi od brata tvog". / Devojka sedi kraj ognja sama i besno sebi govori: / "Ah, mili Bože, da li ima, ima'l što brže od konja?" / "Ludo luda, mlada si, devojko", plamen iz ognja joj govori: / "Ima, luda ludice devojko, brže su oči od konja tvog; / Ludo luda, mlada si devojko, slađi je šećer od meda svog; / Ima, luda ludice devojko, draži je dragi od brata tvog". Moja si!»
} 
musicada d'una cançó popular sèrbia. Era la primera referència que em feia avançar, una cosa que d'alguna manera va fer que la gent d'avui recordés una cançó que fa dos segles era molt coneguda i es cantava per tots els Balcans. A part d'aquesta versió contemporània vaig arribar a la versió original llegint discussions d'un fòrum a Internet. Eren debats entre la gent que es va enfadar amb el músic per haver comès aquest sacrilegi. Sacrilegi o no, en vaig treure les primeres dades sobre la versió original.

El poema efectivament forma part del cançoner popular serbi, publicat per primer cop al llibre Narodna srbska pjesnarica. Čast 2 (Cançoner popular serbi). És el primer poema d'aquest recull de la poesia popular, publicat a Viena l'any 1815. L'autor de la recopilació i de l'edició va ser el filòleg i normativitzador de la llengua sèrbia contemporània, Vuk Stefanović Karadžić. Cito el poema tal com va aparèixer a la pàgina 1 del Cançoner:

\section{RIBA I DJEVOJKA}

Djevojka sjedi kraj mora, Pak sama sebi govori:

"Ah, mili bože i dragi!

Ima l' što šire od mora?

Ima l' što duže od polja?

Ima l' što brže od konja?

Ima l' što slađe od meda?

Ima l' što draže od brata?"

Govori riba iz vode:

"Djevojko luda budalo!

Šire je nebo od mora,

Duže je more od polja,

Brže su oči od konja,

«La noia asseguda sola vora de la mar en veu baixa així es parlava: / "Ah, Déu meu, hi ha res més que la mar més vast?" / “Boja bogeta, ets una noia molt joveneta!", li contesta el peix de l'aigua: / "Sí que hi ha, noieta bojeta, el cel és més vast que la meva mar". / La noia asseguda sola en el camp, a sí mateixa tristament parlava: / "Ah, Déu meu estimat, si tens la resposta / què és lo més volgut que el meu germà?" / "Boja bojeta, ets una noia molt joveneta", l'ocell del camp li contestava: "Sí que hi ha, noieta bojeta, l'amant és més volgut que el teu germà" / La noia asseguda sola vora de la llar a sí mateixa furiosament parlava: / "Ah, Déu estimat, hi ha res més que el cavall més ràpid?" / "Boja bogeta, ets una noia molt joveneta", la flama de la llar li contestava: "Sí que hi ha, noieta bojeta, els ulls són més ràpids que el teu cavall". / "Boja bogeta, ets una noia molt joveneta, el sucre és més dolç que la seva mel; / Sí que hi ha, noieta bojeta, l'amant és més volgut que el teu germà". Ets meva!» (Trad. aut.) 
Slađi je šećer od meda,

Draži je dragi od brata". ${ }^{4}$

(Stefanović Karadžić 1815: 1)

Com que evidentment havia trobat l'original, que s'assemblava força a la traducció carneriana, calia trobar el text intermedi que va fer de pont entre el serbi i el català, ja que sabem del cert que Carner no coneixia cap llengua eslava, i quan tenia dotze anys, encara menys. El cas és que la va traduir d'una font que reduïa considerablement el text de la cançó, perquè en la traducció de Carner hi apareixen tres preguntes i respostes en comptes de les cinc que conté l'original serbi. Carner no diu que la "nina" parla amb ella mateixa, la qual cosa subratlla ben bé la versió original. Parlant amb ella mateixa la noia sèrbia s'adreça a Déu (v. 3). Aquest fet, un element constant de la lírica popular sèrbia, tampoc no és palès a la traducció carneriana. El segon vers en què el peixet s'adreça a la noia (v. 10) no hi figura tampoc. I finalment, en comptes del sucre com a element de comparació de la cosa més dolça que la mel, a la traducció de Carner, sobtadament, hi apareix una abraçada. ¿Es tractava de la traducció d'una variant d'aquesta cançó? ¿De la traducció molt lliure a un dels idiomes propers al català que aleshores podia conèixer Carner? ¿O senzillament existia una cançó semblant que pertanyia a qualsevol altra cultura eslava?

Al començament del segle XIX, després d'haver estat publicat el recull de poesia popular de Vuk Karadžić, es produí un interès enorme per la poesia popular sèrbia. És quan se' $n$ van fer les primeres traduccions a l'alemany, al francès i a l'italià. A més a més, aquesta cultura nova, desconeguda i exòtica, arribà a ser la matèria de molts assajos i estudis de l'època. A banda de les creacions poètiques, també es recollien diverses anècdotes, creences i costums. Molts poetes de l'època quedaren influenciats per les traduccions de la poesia popular sèrbia. A Hongria fins i tot sorgí tota una generació de poetes que escrivien a la «manera sèrbia», que és com s'anomena també aquest moviment poètic dels anys 20. A Finlàndia, Ucraïna, Rússia, també hi ha poetes que pintaren els seus versos de colors de la lírica popular sèrbia (Johan Ludwig Runeberg, Aleksandr Sergejevič Puškin, Taras Ševčenko, Hoffmann von Fallersleben). Als països més propers a Catalunya comptem d'altra banda amb moltes traduccions fetes al llarg del segle XIX.

En explorar la majoria de les traduccions franceses que van aparèixer a l'època i en adonar-me que gairebé totes eren traduccions literals, excloc la possibilitat que una

4 «EL PEIX I LA NOIA / Una noia asseguda vora de la mar / a si mateixa així parlava: / - Ah, Déu estimat i benvolgut! / ¿hi ha res més vast que la mar? / ¿hi ha res més llarg que el camp? / ¿hi ha res més veloç que un cavall? / ¿hi ha res més dolç que la mel? / ¿hi ha res més estimat que un germà? - / El peix de l'aigua així li responia: / - Noieta, boja bogeta! / El cel és més vast que la mar, / la mar és més llarga que el camp, / els ulls són més ràpids que un cavall, / el sucre és més dolç que la mel, / l'amant més estimat que un germà!». És el poema transcrit amb caràcters llatins de l'original en caràcters ciríl lics i segons l'ortografia sèrbia antiga. (Trad. aut.). 
traducció francesa fos el text intermediari. Una d'alemanya tampoc no la podia ser perquè Carner no coneixia aquesta llengua. En castellà no trobo cap referència que indiqui l'existència de cap traducció de les cançons líriques sèrbies en conjunt. Em giro cap a les traduccions a l'italià. I és on em trobo amb un interès considerable per aquesta cançó en concret. Descobreixo un ventall de traduccions força desiguals, la majoria de les quals fetes segons la ja esmentada versió de la cançó recollida per Vuk Karadžić.

En haver consultat tantes traduccions i com que cap d'aquestes no era la resposta exacta a la pregunta sobre la font que va utilitzar Carner, començo a sospitar que el mateix Carner va tallar i versionar la cançó de tal manera que sonés bé en català. Mentrestant, però, m'arriba l'última resposta pendent de la gent de la Universitat de Pàdua, als quals havia demanat que consultessin un llibre antic i rar que hi havia al seu fons bibliotecari. Amb aquesta resposta aparentment arribo a la font desitjada dins del llibre de Ferdinando De Pellegrini Saggio di una versione di canti popolari slavi, publicat a Torí l'any 1846. Però la traducció que en fa Pellegrini no és la font aparent de Carner. Al final del llibre Pellegrini va posar unes notes en les quals reportava, juntament amb un petit estudi sobre la poesia popular dels Balcans, una improvisació ${ }^{5}$ de Paolo Pola que deia:

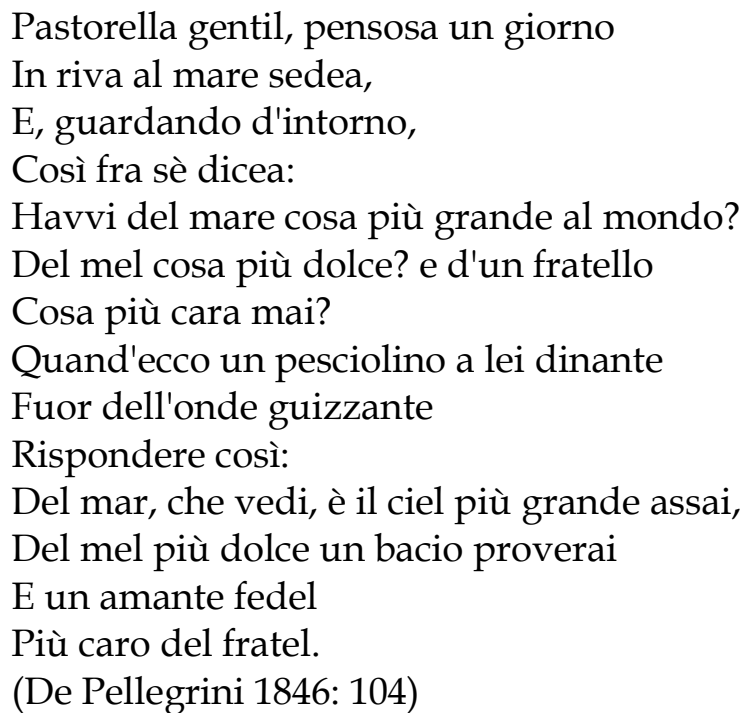

Fins a la celebració del 125è aniversari de Carner, aquesta improvisació representa l'única font i la més ajustada que podia haver utilitzat Carner a l'hora de traduir la cançó al català. Pensava que el text de Pola s'ajustava tan perfectament a la traducció de Carner que semblava evident que n'era el model. I que el poeta es va servir d'un exemplar $\mathrm{d}^{\prime}$ aquest mateix llibre que havia citat o d'un altre que havia transmès el mateix text. Si

\footnotetext{
${ }^{5}$ La improvisació és un gènere poètic i musical que consisteix a improvisar, és a dir cantar versos de manera espontània a partir d'un patró mètric, de rima, d'un tema i/o d'una melodia determinada.
} 
hagués estat així de debò, aquest article intentaria en endavant de convèncer el lector de la versemblança de la font i d'explicar-li les diferències i els canvis que havia fet Carner respecte a la improvisació italiana. El conclouria dient que Carner ja de petit era així de llest i dotat per a poder repintar la cançó popular d'aquest to original que es perd a la improvisació poliana, d'aquesta senzillesa de les cançons sèrbies femenines «che veramente dalle donne sono inventate, massime nel Sirmio é nel Bannato, ove le repetono sul mandolino, rivelando i varj gradi della passione or concitata, or delicata, ma sovratutto patetica» (Cantù 1862-1865: 592).

Cito aquí les paraules de Cantù perquè el tercer volum dels seus Documenti alla Storia Universale és on finalment trobo la font exacta. Cesare Cantù ${ }^{6}$ hi dedica una part significativa del contingut a la poesia popular i, dins d'aquesta, als «Canti slavi» en particular. A més de la traducció en prosa intitulada «La fanciulla e il pesce», a peu de pàgina apareix també l'original de la variant de deu versos octosíl labs de la cançó en qüestió. Hi afegeix també una nota que diu que la cançó té moltes variants en dialectes varis i que ell hi porta la «redazzione illirica» ${ }^{7}$. Com sabrem més tard, el llibre de Cantù és el testimoni imprès més antic conegut d'aquesta variant. En els testimonis posteriors s'intitula «Sidila moma kraj mora» («La mossa asseguda vora de la mar»):

\author{
Sidila moma kraj mora \\ Ter moru ovako govori: \\ Je li što šire od mora? \\ Je li što draže od brata? \\ Je li što slađe od meda? \\ Ribica glavu pomoli, \\ Ter momi ovako govori: \\ Šire je nebo od mora, \\ Draži je dragi od brata \\ Slađi je ljubac od meda. ${ }^{8}$
}

\footnotetext{
${ }^{6}$ Cesare Ambrogio Cantù (1804-1895), historiador, polític, arxiver i escriptor italià. És autor de la Storia Universale, escrita i publicada en 35 volums entre els anys 1838 i 1846. Va ser director de l'Arxiu de la Ciutat de Milà i fundador de l'Arxiu Històric de Llombardia.

${ }^{7}$ Cantù transcriu la cançó plena d'errors. Aquú la cito tal com es va publicar al seu llibre: «Sidjèla moma krai mora / Ter moru ovako govori: / Je li slo sire od mora? / Je li slo sladje od brata? / Je li slo sladje od meda?/ Ribica glavu somoli, / Ter momi ovako govori: / Sirje nebo od mora, / Drazdje dragi od brata / Sladji ljubac od meda.» (Cantù 1862-1865: 594, nota 73).

8 «Una nina asseguda vora de la mar / així a la mar parlava: / ¿Hi ha res més vast que la mar? / ¿res més volgut que un germà? / ¿o res més dolç que la mel? / El peixet en va treure el cap / a la nina li contestava: / El cel és més vast que la mar, / l'amant més volgut que un germà, / un bes més dolç que la mel.» (Trad. aut.)
} 
La traducció que ens hi dóna Cantù és una traducció literal d'aquesta variant, sense pretensions literàries, $\mathrm{i}$ fins i tot en prosa. No tenim dades sobre el traductor, per la qual cosa el considerem Cantù mateix.

\section{LA FANCIULLA E IL PESCE}

Una fanciulla seduta in riva al mare, così parlava: - Avvi egli cosa più vasta del mare? avvi cosa più cara del fratello? avvi cosa più dolce del miele? - Un pesciolino emerse dall'acqua, e alla fanciulla rispose: - Il cielo è più vasto del mare; l'amante è più caro del fratello; il bacio è più dolce del miele. (Cantù 1862-1865: 593-594)

En el pròleg del mateix llibre, parlant dels motius de la poesia popular, Cantù hi cita també la traducció de la versió que forma part del Cançoner popular serbi de Vuk Karadžić 9 . Per tant, és molt curiós el fet que Carner triés la variant menys coneguda i que, traduint-la, s'hi basés exclusivament, que era la variant menys coneguda i divulgada per l'Europa del moment.

El llibre de Cantù va ser traduït al castellà entre 1854 i 1859. Evidentment, va ser el llibre que Carner tenia a les mans en traduir ell, ja que posteriorment va ser la font que utilitzés sovint. Quan ja hem fet un recorregut de recerca, com en molts casos, ens assabentem que la resposta era molt més fàcil i propera d'allò que ens la pensàvem. Don Nemesio Fernández Cuesta tradueix així la cançó al castellà:

\section{LA NIÑA Y EL PEZ}

Una niña sentada á orillas del mar, hablaba así: - ¿Hay algo que sea mas vasto que el mar? ¿Hay algo mas querido que un hermano? ¿Hay algo mas dulce que la miel? Un pececillo salió del mar, y contestó á la niña: - El cielo es mas vasto que el mar; el amante mas querido que el hermano; el beso mas dulce que la miel. (Fernández Cuesta 1858: 761).

És d'aquí concretament d'on treurà Carner la seva traducció quatre dècades més tard.

\section{Sobre la variant «Sidila moma kraj mora»}

Segons les paraules del filòleg croat Jakša Ravlić, aquesta variant representa, amb tot, la forma més antiga de la cançó que va incloure Vuk Karadžić al Cançoner popular serbi.

\footnotetext{
9 «Anche la Serviana, seduta sulla spaiggia, canta: “Qual cosa v'é più vasta dell'immenso mare, più lunga della prateria, più rapida del corsiero, più dolce del miele, più cara d'un fratello?" E un pesce emerso dell'acqua le risponde: "O fanciulla, tu se' pure smemorata! Il cielo è più vasto del mare, il mare più lungo della prateria, l'occhio più rapido del corsiero, il zucchero più dolce del miele, l'amante più caro del fratello".» (Cantù 1862-1865: 25)
} 
Estretament vinculada al mar, hom pensa que prové de Dubrovnik. És exactament on s'acaben les nombroses illes de Croàcia i el mar pren l'aspecte de la cosa més vasta del món. A més, la variant conté les formes típiques de la parla local de Dubrovnik. Com explica detingudament Ravlić, la cançó va ser traduïda primerament al llatí l'any 1798 per Juraj Ferić (1739-1820). Aquest llatinista de Dubrovnik la va incloure a la seva epístola escrita a l'historiador alemany Joannes Müller («Ad clarissimum Joannem Müller... epistola»), juntament amb la resta de 34 traduccions més de poemes lírics populars de la mateixa regió. Cito aquí la traducció de Ferić, intitulada «Dialogus puellae cum mari»:

Sedens puella in littore;
Mari inquiebat caerulo:
Num te quid est patentius?
Num melle quid suavius?
Num fratre quid est dulcius?
Piscis, qui ab unda protulit
Caput, puellae reddidit:
Coelum mari patentius,
Melle osculum suavius,
Fratre est amator dulcior.
(Ferić $1798 \cdot 38-39$ )

Llavors la cançó apareix a Itàlia cap al 1825 al llibre de Marco Faustino Gagliuffi (1765-1834), també llatinista ragusà. Aquesta forma és exactament la versió improvisada de Paolo Pola, ja esmentada en aquest article, que hi apareix com a «originale». No se sap ben bé com es va produir aquesta confusió sobre l'autoria de la cançó, però Ravlić suposa que Gagliuffi en té la culpa. Com a creador de la segona traducció de la cançó al llatí10, devia haver-ne conegut anteriorment l'original. Per tant, es considera el transmissor de la cançó a Itàlia, però igualment se li pot adscriure el mèrit d'haver creat la versió improvisada que va recitar Pola la nit de Nadal de 1825 al saló de la comtessa Izabela Albrizzi.

A la seva carta a Ljudevit Gaj ${ }^{11}$ de 27 de març de 1834, Anton Kaznačić (1784-1874), advocat a Dubrovnik, exposa, provocat exactament per l'adopció injusta de la cançó pels italians, que la cançó forma part de la creació popular croata. A efectes justificatoris, la

\footnotetext{
10 «Sola sedens tacito in litore virgo, / An quid, dicebut, grandius est pelago? / Dulcius an melle est? An fratre est carius uno? / Cui parvus piscis talis verba dedit: / Audi! Aether vincit pelagum, mel oscula vincunt, / Fratrem unum, o virgo, vincit amatus amans».

${ }^{11}$ Ljudevit Gaj (1809-1872), lingüísta, polític, periodista i escriptor croata. Va ser la figura central de la reformació nacional croata anomenada Moviment Il liri (1835-1849).
} 
cita en llengua original, ajustada, però, a l'ortografia de la llengua italiana ${ }^{12}$. Vet aquí el testimoni escrit més antic conegut de la variant.

El primer testimoni imprès és, tanmateix, a la primera edició del llibre de Cantù. El fet que hi report l'original només d'aquesta cançó i d'altres no, i els errors que hi fa transcrivint-lo, indica que no l'havia presa d'un testimoni escrit, sinó que era sentida d'algun dels nombrosos viatgers croats que passaven per l'Itàlia del nord per afers diversos. Al llibre no figura el traductor de la cançó eslava, per la qual cosa, com he dit, cal adscriure'n la traducció al mateix Cantù. Ell la tradueix literalment, sense cap més pretensió literària que preservar-ne el to senzill i transmetre'n el contingut intacte. Cantù la posa en prosa per evitar les inexactituds que de ben segur que es produirien intentant d'ajustar el vers a un nombre concret de síl labes. A més, hi comenta que les variants de la cançó són nombroses en els diversos dialectes i els territoris varis dels Balcans. En el seu treball, Ravlić fa una classificació assenyada i argumentada i en treu cinc formes, de les quals la variant que reporta Cantù n'és una i la que publica Karadžić n'és una altra: la més elaborada, literària, amb una estructura més monumental, més complexa i de contingut més acostat al paisatge continental de la península Balcànica. La variant que reporta Cantù, costanera i òbviament la més antiga, a Croàcia es publicà per primer cop a Zagreb, en el citat article de Jakša Ravlić de 1954.

És interessant l'argumentació que fa Ravlić sobre la possible evolució de la cançó, que, segons el motiu principal, sens dubte neix al costat del mar. Llavors, segons ell, s'expandeix cap a l'interior, on sorgeix la versió en què la major importància la tenen els elements terrestres (camp, cavall). Són els elements existencialment substancials del poble continental, com ho són el mar i el vaixell als pobles costaners. Ravlić situa el naixement de la versió allargada a la Vall del Pop (Popovo polje), que és la vall més a la vora de Dubrovnik, relativament gran, que pel seu aspecte representa un contrast considerable amb el paisatge muntanyós i rocós de la regió. Aquesta vall o aquest camp, com diu la cançó, efectivament té una forma allargada i pot ser la característica de la qual concretament prové aquesta comparació.

La diferència entre les dues variants de la cançó que desperta més curiositat i n'és un dels elements substancials, és el canvi de la paraula «petó» pel «sucre». Ravlić l'explica així:

čini se da je onaj koji je dopunjao ovu verziju, bio jedan od onih, koji su u XVII. i XVIII. vjeku prekrajali lirske narodne pjesme da bi iz njih izbacili tobože lascivne elemente ili su

12 "Sidila moma kraj morra, / momizza morru govori: / jelli scto scirre od morra? / jelli scto drasge od bratza?/ jelli scto sladje od meda? // Ribiza glavom pomoli / iz mora, i momi govori: / scire je nebo od morra, / drasgi je draghi od bratza, / slaghi je zelov od medda." 
pjevali nove, da bi potisnuli narodne pjesme, koje su preotimale maha, jer ih je narod volio. ${ }^{13}$ (Ravlić 1954: 252).

A més de l'ampliació considerable de cinc versos que té la variant posterior recollida per Vuk (cinc preguntes i respostes en comptes de tres), es nota al segon vers una desigualtat semàntica: la nina de la costa parla al mar i la del camp parla a si mateixa adreçant-se a Déu.

Anteriorment a 1896, quan apareix la traducció de Carner, s'havien publicat fins i tot vuit traduccions d'aquesta cançó a l'italià. Les enumero cronològicament:

1. Paolo Pola, "Pastorella gentil”, dins F. Gagliuffi, Specimen de Fortuna latinitatis accedunt Poemata varia meditata et extemporalia, Auguste Tavrinorum, 1833.

2. Carlo Fioravanti, "La fanciulla e il pesce", La favilla, Trieste, 15-VI-1842.

3. Fernando Pellegrini, "La fanciulla e il pesce", dins Gazzetta di Zara, núm. 19, 1844, i dins Saggio di una versione di Canti popolari slavi, Torí, 1846.

4. Cesare Cantú, "La fanciulla e il pesce", dins Documenti alla Storia Universale, Tomo Terzo, Torí, 1846.

5. Giovani de Rubertiso, “La donzella e il pesce”, 1869.

6. Felice Uda, "La fanciulla e il pesce", dins Melidie intime, Milà, 1877.

7. Giacomo Chiudina, "Il pesciolino e la fanciulla", en Canti del popolo slavo, vol. II, Florència, 1878.

8. Pietro Turati, “In riva al mare”, dins Canti popolari slavi, greci e napolitani, Milà, 1883.

La nostra es considera la cançó popular eslava més traduïda mai a l'italià. Totes les traduccions esmentades són força diferents i desiguals entre elles, i clarament indiquen l'existència de nombroses variants de la cançó, orals o escrites, escampades arreu dels Balcans.

L'única traducció al català coneguda fins ara és la que va fer indirectament Carner, servint-se de la traducció castellana. A continuació veurem les seves peculiaritats respecte a la font castellana i a l'original croat.

\section{La traducció de Carner}

Ara que ja hem establert la font i hem trobat que entre la traducció de Carner i l'original almenys hi ha dues traduccions intermediàries (la italiana i la castellana),

\footnotetext{
13 «sembla que ell que omplia aquesta versió, era un dels qui als segles XVII i XVIII, remodelaven cançons líriques populars per treure'n elements motejats lascius, o en cantaven de noves, per reprimir les cançons populars que regnaven, perquè al poble li agradaven.» (Trad. aut.)
} 
intentaré reconstruir la feina de Carner, per tal de mostrar el camí que va recórrer la cançó del castellà al català. Així mateix, consideraré l'original croat que coneixia Carner de la mateixa font, encara que no el podia entendre.

Partim del títol, on Carner no fa cap canvi respecte a la seva font. Es pot qüestionar, però, per què Cantù intitula la seva traducció «La fanciulla e il pesce» si en realitat no és el títol de la variant croata que ens hi reporta. La variant croata és coneguda sota el títol «Sidila moma kraj mora» («La mossa asseguda vora de la mar»), però pot ser que antigament també fos coneguda com a «Riba i djevojka» («La noia i el peix»).

Pel que fa a l'estructura i l'ordre de les preguntes i respostes, tampoc no hi ha divergències, la qual cosa reafirma la hipòtesi sobre la versió de Cantù com a font de Carner. De l'altra banda, trobem a «La nina y el peix» algunes paraules o versos sencers que no existeixen a l'original ni en Cantù. Per tant, podem parlar sobre la traducció carneriana com a traducció-recreació dels versos de la cançó popular croata traduïda al castellà, ja que el seu traductor al català té certes preocupacions poètiques que al poble creador no li interessaven pas. No obstant això i a diferència de la versió castellana, Carner dona a la seva versió un to força popular i típic de la poesia del poble. A continuació veurem com ho fa, com poetitza la traducció de Cantù (és a dir la de Nemesio Fernández Cuesta) i li retorna un tros d'aquell charme popular, melòdic i senzill.

Respecte a la versió en prosa que utilitza Carner com a base de la seva recreació, diríem que intenta omplir els buits poètics que té aquest argument prosaic. Partint de la suposada voluntat de Carner de fer-ne una composició poètica popular, i segons la divisió en versos que fa, faig un «esquelet» de la versió castellana per facilitar la comparació. Les mancances poètiques hi són evidents:

LA NINA Y EL PEIX

Una bella nina

n'estava sentada

vora de la mar,

4 vora la mar blava,

y ab sa dolsa veu

aixís ne parlava:

-¿Hi ha alguna altre cosa

8 que la mar, mes vasta?

$¿$ Hi ha alguna cosa

que sia estimada

com un bon germà,

12 com una germana?

\section{LA NIÑA Y EL PEZ}

Una niña

Sentada

á orillas del mar,

hablaba así:

- ¿Hay algo que sea

mas vasto que el mar?

¿Hay algo mas querido

que un hermano?
SIDILA MOMA KRAJ

MORA

Sidila moma krai mora
Ter moru ovako govori:

Je li što šire od mora?

Je li što slađe od brata? 
¿O que hi ha mes dols

que la mel? - Del aygua

va sortir un peixet

16 qu'aixís contestava:

- Lo cel es mes vast

qu'aquesta mar blava

l'aymant mes volgut

20 qu'un germà o germana

mes dolsa que la mel

n'es una abrassada.
¿Hay algo mas dulce

que la miel?

Un pececillo salió del mar,

y contestó á la niña:

- El cielo es mas vasto

que el mar;

el amante mas querido

que el hermano;

el beso mas dulce

que la miel.
Je li što slađe od meda?

Ribica glavu pomoli,

Ter momi ovako govori:

Šire je nebo od mora,

Draži je dragi od brata

Slađi je ljubac od meda.

Poso al costat la cançó en llengua original com a referència estructural i mètrica. Podríem dir que Carner duplica el nombre de versos respecte a la versió original: a cada octosíl lab croat hi corresponen dos pentasíl labs catalans. Els primers quatre versos carnerians, però, responen al primer vers original. És on Carner intercala dos versos inexistents a l'orginal i a la traducció castellana. Suposem que ho fa per completar la imatge introductòria que li semblava incompleta $\mathrm{o}$, simplement, per apropar-la a una melodia més popular i cantable. Els versos continuen segons la regla que acabo d'establir, fins al vers núm. 12, on, com a element de comparació, juntament amb el germà, hi a pareix també la germana, per tal d'aconseguir la rima assonant, de la qual cosa en surten dos versos més. El vers 14 queda tallat per la introducció del peixet. Aquesta introducció ocupa l'altra meitat del vers i dos versos següents en comptes de quatre, que li correspondrien segons la regla fins aquí establerta. Fins al final, segons el número de versos, no hi ha irregularitats.

Evidentment Carner en vol fer una composició que rima, que s'assembla mètricament a la poesia popular, per tal que es pugui cantar. Són posades en cursiva les parts que hi introdueix Carner, condicionat pel vers pentasíl lab i la rima assonant en els versos parells. Per atènyer aquests dos ideals mètrics, en la traducció de Carner sorgeixen uns quants epítets que ens donen una imatge poètica més rica i acolorida. Així ens explica Carner que la nina és «bella», que «parla amb una veu dolça»; que la mar és «blava» i que un germà, si no és bo, no és un referent ideal per comparar-lo amb la cosa més estimada del món.

És curiós que la traducció de Carner representa el primer cas i l'únic en què, com a cosa més dolça del món, hi figura una abraçada. És un element nou amb què el poeta, d'una manera completament gratuïta, substitueix l'antic element de la font (un bes). És una innovació que no admet com a pretext les pretensions literàries i mètriques d'aconseguir la rima o el pentasíl lab. Per què el poeta utilitza una paraula diferent si té a 
l'abast la paraula «besada», que substitueix perfectament la paraula castellana «beso» i a més respon a les necessitats versificadores? Podem suposar que el significat de la paraula «besada» va ser massa fort per a un nen de dotze anys i d'educació catoliquíssima, i per tant l'havia d'evitar com fos i trobar una paraula més acceptable, menys comprometedora.

Restarà per sempre el misteri de com va interessar a Carner aquesta cançó, i com i per què va decidir traduir aquesta en concret i no cap altra. Potser són la seva senzillesa i el to directe que el van seduir, potser quelcom diferent. Tot i que es tracta d'una traducció indirecta, la traducció de Carner representa l'única traducció catalana d'aquesta cançó coneguda fins ara, i molt probablement és així mateix la primera i l'única creació de la poesia popular dels Balcans que s'hagi traduït mai al català.

\section{BIBLIOGRAFIA}

Cantù, Cesare. Documenti alla Storia Universale. Tomo III. Torino: Unione TopograficoEditrice, 1862-1865. Stampato.

De Pellegrini, Ferdinando. Saggio di una versione di canti popolari slavi. Torino: Stabilimento tip. Fontana, 1846. Stampato.

Ferić, Juraj. Ad clarissimum virum Joannem Muller Georgii Ferrich Ragusini epistola. Huic accedunt illyricæ linguæ poematia triginta septem latinis carminibus ab eodem reddita. Dubrovnik: A. Trevisan, 1798. Versio typis.

Fernández Cuesta, D. Nemesio. Historia universal por César Cantú. Tomo IX. Madrid: Imprenta de Gaspar y Roig editores, 1858. Impreso.

«La nina y el peix.» L'Aureneta, II. 70 (6-VI-1896): 3. Imprès.

Nedić, Vladan. «Prva Karadžićeva knjiga Srpskih narodnih pjesama.» Srpske narodne pjesme. Vuk Stefanović Karadžić. Beograd: Prosveta, 1975. 627-664. Štampano.

Ravlić, Jakša. «O hrvatskoj narodnoj pjesmi 'Sidila moma kraj mora'.» Zbornik za narodni život i običaje Južnih Slavena. Knj. 38. O 250. godišnjici rođenja fra Andrije Kačića Miošića. Zagreb: JAZ, 1954. 233-259. Štampano.

Stefanović Karadžić, Vuk. Narodna srbska pjesnarica. Čast 2. Viena: Pečašnja Joanna Šnirera, 1815. Štampano.

Van Gogh. «Ludo Luda.» YouTube, postavio mike1100110, 26.05.2008. Web. 18.03.2021. 